\title{
High pleural fluid hyaluronan concentrations in rheumatoid arthritis
}

\author{
T. Söderblom*, T. Pettersson*, P. Nyberg**, A.M. Teppo*, L. Linko**, H. Riska ${ }^{+}$
}

\begin{abstract}
High pleural fluid hyaluronan concentrations in rheumatoid arthritis. T. Söderblom, T. Pettersson, P. Nyberg, A.M. Teppo, L. Linko, H. Riska. (C)ERS Journals Ltd 1999. ABSTRACT: Previous studies have shown that high pleural fluid (Pf) hyaluronan (HYA) concentrations may be due not only to malignant mesothelioma but also to inflammatory diseases. The objective of this study was to evaluate Pf-HYA in various nonmalignant inflammatory pleural disorders.

A radiometric assay was used to determine HYA in Pf and serum (S) of 126 patients, 12 of whom had rheumatoid arthritis (RA), 22 tuberculosis, 22 pneumonia, 41 lung cancer, 10 malignant mesothelioma and 19 congestive heart failure. Pf-HYA values were correlated with values for Pf-tumour necrosis factor (TNF)- $\alpha$ and Pf-interleukin (IL)-1 $\beta$, as determined by radioimmunoassay.

The highest median Pf-HYA (125.6 mg $\cdot \mathrm{L}^{-1}$, range $\left.0.04-386.5 \mathrm{mg} \cdot \mathrm{L}^{-1}\right)$ occurred in patients with malignant mesothelioma. Among patients with nonmalignant inflammatory diseases, significantly higher median Pf-HYA were observed in those with rheumatoid arthritis $\left(64.2 \mathrm{mg} \cdot \mathrm{L}^{-1}\right.$, range $\left.25.8-106.9 \mathrm{mg} \cdot \mathrm{L}^{-1}\right)$ than in those with tuberculosis (25.5 mg $\cdot \mathrm{L}^{-1}$, range $\left.14.9-57.1 \mathrm{mg} \cdot \mathrm{L}^{-1}, \mathbf{p}<0.0005\right)$ or pneumonia $\left(20.9 \mathrm{mg} \cdot \mathrm{L}^{-1}\right.$, range 9.5-129.4 mg $\left.\cdot \mathrm{L}^{-1}, \mathbf{p}<\mathbf{0 . 0 0 5}\right)$. There was no correlation between Pf-HYA and S-HYA. Pf-HYA correlated positively with Pf-TNF- $\alpha(r=0.62)$ and Pf-IL-1 $\beta(r=0.52)$.

High pleural fluid hyaluronan occurs not only in malignant mesothelioma, but also in certain nonmalignant inflammatory diseases, especially rheumatoid arthritis. One explanation for the increase in pleural fluid hyaluronan may be local production of proinflammatory cytokines, such as tumour necrosis factor- $\alpha$ and interleukin-1 $\beta$. Eur Respir J 1999; 13: 519-522.
\end{abstract}

*Dept of Medicine, Division of Pulmonary Medicine, Internal Medicine and Nephrology, Helsinki University Central Hospital, Helsinki, Finland. **Mjölbolsta Hospital, Finland. ${ }^{+}$Dept of Medicine, Akademiska sjukhuset, Uppsala, Sweden.

Correspondence: T. Pettersson

Dept of Medicine

Haartmaninkatu 4

Box 340, FIN-00029

Helsinki University Central Hospital

Finland

Fax: 35894714616

\section{Keywords: Hyaluronan}

pleural effusion

rheumatoid arthritis

Received: May 281998

Accepted after revision November 71998
Hyaluronan (HYA), a long-chained unbranched polysaccharide composed of repeated dimers of D-glucuronic acid and $\mathrm{N}$-acetylglucosamine, is widely distributed in all connective tissues. The molecule forms a continuous network, which accounts for its physiological properties such as viscoelasticity, filtration effects, regulation of the osmotic pressure, and protection against the spread of infectious agents. In synovial fluid, HYA is responsible for lubricating and protecting the joint during movement. The healthy pleural membrane produces HYA in order to reduce the friction between the parietal and the visceral pleura during lung movements.

Synovial cells from patients with rheumatoid arthritis (RA) produce larger quantities of HYA than synovial cells from healthy persons [1], and particularly high levels of HYA occur in rheumatoid synovial fluid [2]. The synovial cell HYA production is stimulated by tumour necrosis factor (TNF)- $\alpha$ and interleukin (IL)-1 $\beta$, both pivotal mediators of rheumatoid joint inflammation and destruction [3]. Elevated serum (S) levels of HYA have been reported in various conditions such as liver disease [4], RA [5], psoriasis [6], scleroderma [7], septicaemia [8], adult respiratory distress syndrome [9], and malignant mesothelioma [10].

A high concentration of HYA in pleural fluid (Pf) is suggestive of a diagnosis of malignant mesothelioma [11, 12]. In a previous study, a high Pf-HYA in some patients with benign inflammatory diseases was seen [13]. The aims of the present study were to analyse Pf-HYA in a large number of patients with inflammatory diseases, including RA, and to investigate whether there is a correlation between HYA and TNF- $\alpha$ and IL- $1 \beta$ in pleural fluid.

\section{Materials and methods}

Pleural fluid and serum samples for HYA determinations were collected consecutively from patients admitted for a diagnostic evaluation of a pleural effusion. In the final analysis, patients with an uncertain diagnosis or patient groups too small to be suitable for statistical analysis were not included. The number of patients with RA and patients with mesothelioma was increased by including patients outside the consecutive series. Thus, the population investigated included 12 patients with RA, 22 with tuberculosis, 22 with pneumonia, 41 with lung cancer, 10 with malignant mesothelioma and 19 with congestive heart failure (CHF).

Patients with RA fulfilled the revised criteria of the American College of Rheumatology [14]. Clinical data of the RA patients are shown in table 1. Tuberculosis was verified by a positive staining or culture for Mycobacterium tuberculosis in pleural fluid or sputum, and/or by pleural biopsy findings compatible with tuberculosis. The 
Table 1. - Clinical data of 12 patients with rheumatoid arthritis

\begin{tabular}{|c|c|c|c|c|c|c|c|c|}
\hline Sex & $\begin{array}{l}\text { Age } \\
\text { yrs }\end{array}$ & $\begin{array}{l}\text { Rheumatoid } \\
\text { factor* }\end{array}$ & $\begin{array}{l}\text { Duration of joint } \\
\text { disease prior to } \\
\text { pleurisy } \\
\text { yrs }\end{array}$ & $\begin{array}{c}\text { First manifestation } \\
\text { of RA }\end{array}$ & $\begin{array}{l}\text { Pf-protein } \\
\mathrm{g} \cdot \mathrm{L}^{-1}\end{array}$ & $\begin{array}{l}\text { Pf-glucose } \\
\mathrm{mmol} \cdot \mathrm{L}^{-1}\end{array}$ & $\begin{array}{l}\text { Pf-LDH } \\
U \cdot L^{-1}\end{array}$ & $\begin{array}{l}\mathrm{Pf}-\mathrm{C} 4 \\
\mathrm{~g} \cdot \mathrm{L}^{-1}\end{array}$ \\
\hline M & 51 & Positive & 0 & Pleurisy & 49 & 1.2 & 1167 & 0.02 \\
\hline M & 54 & Positive & 3 & Arthritis & 39 & 0.3 & 944 & 0.01 \\
\hline $\mathrm{F}$ & 63 & Positive & 6 & Arthritis & 60 & 0.2 & 4157 & 0.01 \\
\hline M & 62 & Positive & 5 & Arthritis & 55 & 2.3 & 1657 & 0.14 \\
\hline M & 60 & Positive & 2 & Arthritis & 54 & 0.2 & 364 & 0.08 \\
\hline $\mathrm{F}$ & 51 & Positive & 34 & Arthritis & 52 & 0.5 & 3229 & 0.02 \\
\hline M & 51 & Positive & 1 & Arthritis & 76 & 0.1 & 6472 & 0.01 \\
\hline M & 57 & Positive & 0 & Pleurisy & 58 & 4.1 & 1981 & 0.03 \\
\hline $\mathrm{F}$ & 54 & Positive & 22 & Arthritis & 47 & 0 & 3925 & 0.01 \\
\hline $\mathrm{F}$ & 72 & Positive & 56 & Arthritis & 46 & 3.0 & 1321 & 0.13 \\
\hline M & 60 & Positive & Unknown & Arthritis & 64 & 2.5 & 1555 & 0.03 \\
\hline M & 44 & Positive & 1.5 & Arthritis & 45 & 0 & 1421 & 0.02 \\
\hline
\end{tabular}

*: Determined by the Waaler-Rose sheep red cell agglutination test. RA: rheumatoid arthritis; Pf: pleural fluid; LDH: lactate dehydrogenase; C4: complement component 4 .

diagnoses of pneumonia and CHF were based on the clinical course of the diseases and on a favourable response to antimicrobical and diuretic therapy, respectively. Seventeen of the 19 patients with CHF had symptoms of recent onset, whereas two had chronic effusions with a duration of approximately 4 and 12 months, respectively. The diagnosis of carcinomatous pleural effusion was based on the demonstration of tumour cells in Pf or on pleural biopsy or on the exclusion of any other specific diagnosis in a patient with verified lung cancer. The diagnosis of mesothelioma was verified histologically; there were five sarcomatous mesotheliomas, one epithelial and four unclassified. At the time of diagnosis, each of the mesotheliomas was confined to a single side of the thoracic cavity.

No patient had overt hepatic failure. Among the 19 patients with $\mathrm{CHF}$, the two with a long-standing pleural effusion had hepatomegaly and ascites, respectively. In two patients with lung cancer, ultrasound or computed tomography (CT) showed liver metastases, but no patient with cancer had hepatic dysfunction.

Pleural fluid samples were obtained by intercostal needle aspiration under local anaesthesia. The samples were stored at $-20^{\circ} \mathrm{C}$ until assayed. Pleural biopsies were taken percutaneously with the Abrams' needle, or on thoracoscopy or thoracotomy. Serum samples were taken concomitantly. Pf-HYA and S-HYA were determined radiometrically by the highly sensitive and specific Pharmacia HA test 50 (Pharmacia Diagnostics AB, Uppsala, Sweden). According to the manufacturer, the detection limit of the test is 5 $\mu \mathrm{g} \cdot \mathrm{L}^{-1}$, the reference range for normal human serum $12-83$ $\mu \mathrm{g} \cdot \mathrm{L}^{-1}$, the range of intra-assay variation $4.5-6.5 \%$, the range of interassay variation $4.9-8.5 \%$ and the recovery range from serum $81-118 \%$. Solid-phase double antibody radioimmunoassays were used to analyse Pf-TNF- $\alpha$ [15] and Pf-IL-1 $\beta$ [16], which were measured in 41 patients with inflammatory disease and in nine patients with lung cancer. The upper limits of normal human serum concentrations of TNF- $\alpha$ and IL-1 $\beta$ were $40 \mathrm{ng} \cdot \mathrm{L}^{-1}$ and 20 $\mathrm{ng} \cdot \mathrm{L}^{-1}$, respectively. Statistical calculations were performed with Mann-Whitney's U-test and Spearman's correlation test.

\section{Results}

The highest median Pf-HYA occurred in patients with mesothelioma $\left(125.6 \mathrm{mg} \cdot \mathrm{L}^{-1}\right.$, range $\left.0.04-386.5 \mathrm{mg} \cdot \mathrm{L}^{-1}\right)$ and in those with RA $\left(64.2 \mathrm{mg} \cdot \mathrm{L}^{-1}\right.$, range $\left.25.8-106.9 \mathrm{mg} \cdot \mathrm{L}^{-1}\right)$. The difference between these two groups was not significant. The highest single Pf-HYA values were seen in patients with mesothelioma. The median Pf-HYA was significantly higher in patients with RA than in patients with CHF (7.5 mg. $\mathrm{L}^{-1}$, range $\left.1.3-14.3 \mathrm{mg} \cdot \mathrm{L}^{-1}, \mathrm{p}<0.0001\right)$, tuberculosis $\left(25.5 \mathrm{mg} \cdot \mathrm{L}^{-1}\right.$, range $\left.14.9-57.1 \mathrm{mg} \cdot \mathrm{L}^{-1}, \mathrm{p}<0.0005\right)$, lung cancer $\left(20.1 \mathrm{mg} \cdot \mathrm{L}^{-1}\right.$, range $\left.2.7-77.4 \mathrm{mg} \cdot \mathrm{L}^{-1}, \mathrm{p}<0.0005\right)$ and pneumonia $\left(20.9 \mathrm{mg} \cdot \mathrm{L}^{-\mathrm{P}}\right.$, range $9.5-129.4 \mathrm{mg} \cdot \mathrm{L}^{-1}, \mathrm{p}<$ $0.005)$. There was considerable overlap between the groups (fig. 1).

Only in RA and in CHF did the median S-HYA exceed the upper limit of the normal range. No patient had a SHYA $>1.0 \mathrm{mg} \cdot \mathrm{L}^{-1}$ (table 2 ), and there was no correlation between the levels of Pf-HYA and S-HYA.

The highest median Pf-TNF- $\alpha$ and IL- $1 \beta$ were seen in patients with RA (table 3 ). Positive correlations occurred

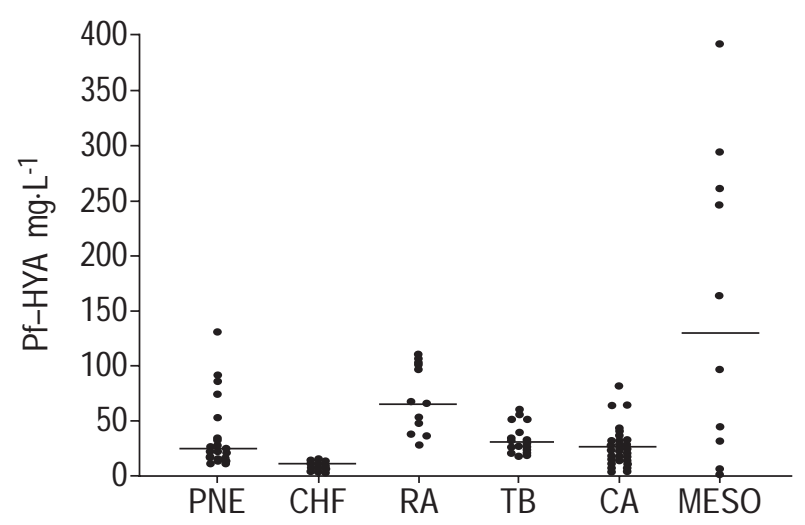

Fig. 1. - Pleural fluid hyaluronan concentrations in 126 patients with pleural effusions of various causes. The horizontal lines represent the median values in each group. Pf-HYA: pleural fluid hyaluronan concentration; PNE: pneumonia; CHF: congestive heart failure; RA: rheumatoid arthritis; TB: tuberculosis; CA: cancer; MESO: malignant mesothelioma. 
Table 2. - Serum hyaluronan concentrations in patients with pleural effusions of various causes

\begin{tabular}{lccc}
\hline Diagnosis & $\mathrm{n}$ & $\begin{array}{c}\text { Median } \\
\mu \mathrm{g} \cdot \mathrm{L}^{-1}\end{array}$ & $\begin{array}{l}\text { Range } \\
\mu \mathrm{g} \cdot \mathrm{L}^{-1}\end{array}$ \\
\hline Rheumatoid arthritis & 12 & 93 & $17-500$ \\
Malignant mesothelioma & 10 & 54 & $35-228$ \\
Tuberculosis & 22 & 46 & $15-121$ \\
Lung cancer & 41 & 60 & $21-371$ \\
Pneumonia & 22 & 47 & $17-163$ \\
Congestive heart failure & 19 & 132 & $51-772$ \\
\hline
\end{tabular}

Reference range for hyaluronan in normal human serum: $12-83$ $\mu \mathrm{g} \cdot \mathrm{L}^{-1}$.

between Pf-HYA and Pf-TNF- $\alpha(\mathrm{r}=0.62, \mathrm{n}=50)$, and between Pf-HYA and Pf-IL-1 $\beta(r=0.52, n=50)$.

\section{Discussion}

The major observation of the present study was that high concentrations of HYA occur in rheumatoid pleural effusions. In fact, the median Pf-HYA was higher in RA than in any other benign inflammatory disease or in neoplastic diseases other than mesothelioma. A high Pf-HYA has been considered characteristic of malignant mesothelioma [11], especially mesothelioma of the epithelial type [17]. In accord with the present study, RA should be kept in mind as another possible cause of an abundance of HYA in pleural fluid. Determination of Pf-HYA is, however, of little value in the diagnosis of rheumatoid pleurisy, where the clinical picture and the characteristically low glucose concentration, low $\mathrm{pH}$, and low concentrations of complement components $\mathrm{C} 3$ and $\mathrm{C} 4$ in pleural fluid establish the cause.

HYA is synthesized in all tissues of mesenchymal origin. In the synovium, it is produced by synovial cells and fibroblasts, and in the pleural membrane by mesothelial cells. Corticosteroid therapy seems to have an inhibitory effect on HYA production [5], but otherwise little is known about the regulation of the in vivo synthesis of HYA According to tissue culture studies, several hormones such as insulin, parathyroid hormone, calcitonin and testosterone activate HYA synthesis, whereas oestrogens and corticosteroids have an inhibitory effect [18]. Human synovial fibroblasts in cell cultures are known to produce HYA when stimulated with IL- $1 \alpha$, IL- $1 \beta$, TNF- $\alpha$, TNF- $\beta$ and

Table 3. - Pleural fluid tumour necrosis factor (TNF)- $\alpha$ and interleukin (IL)-1 $\beta$ concentrations in patients with pleural effusions of various causes

\begin{tabular}{|c|c|c|c|}
\hline Diagnosis & $\mathrm{n}$ & $\begin{array}{l}\text { TNF- } \alpha \\
\mathrm{ng} \cdot \mathrm{L}^{-1}\end{array}$ & $\begin{array}{l}\mathrm{IL}-1 \beta \\
\mathrm{ng} \cdot \mathrm{L}^{-1}\end{array}$ \\
\hline id arthritis & 5 & $212(185-361)$ & $1600(9$ \\
\hline Tuberculosis & 19 & $176(11$ & $1200(8$ \\
\hline Lung & 9 & $169(1$ & $900(7$ \\
\hline Pneumonia & 8 & $152(95-225)$ & $1000(300-2000)$ \\
\hline $\begin{array}{l}\text { Congestive heart } \\
\text { failure }\end{array}$ & 9 & $97(76-179)$ & $800(200-1100)$ \\
\hline
\end{tabular}

The upper limits of serum TNF- $\alpha$ and IL- $1 \beta$ concentrations in normal human serum: $40 \mathrm{ng} \cdot \mathrm{L}^{-1}$ and $20 \mathrm{ng} \cdot \mathrm{L}^{-1}$, respectively. Data presented as median (range). transforming growth factor- $\beta_{1}[3,19,20]$. Since pro-inflammatory cytokines are known to stimulate HYA synthesis, the positive correlations observed between pleural fluid HYA and TNF- $\alpha$ and IL-1 $\beta$, respectively, were predictable. HYA has been supposed to participate in the regulation of inflammation through its feedback induction of IL-1 production [21], with its inhibitory effects on inflammatory events such as polymorphonuclear leukocyte chemotaxis and macrophage phagocytosis and its scavenging of free oxygen radicals [22]. HYA has a beneficial effect on wound healing by regulating angiogenesis [23] and modifying cellular migration.

In many inflammatory and infectious diseases there is a local accumulation of HYA in various body fluids. Examples include bronchoalveolar lavage fluid in hypersensitivity pneumonitis [24] and pulmonary sarcoidosis [25], intestinal lavage fluid in coeliac disease [26], peritoneal fluid in genital inflammation [27], and parapneumonic pleural fluid [28]. High Pf-HYA levels in infectious pleural effusions have been claimed to represent false positive results of the radioassay owing to a possible interaction of the HYA binding protein with bacterial capsulae [12]. There are very few reports on Pf-HYA in systemic disease, but in the report by HiLlerdal et al. [28] the Pf-HYA of two patients with systemic lupus erythematosus (SLE) was clearly lower than the median Pf-HYA of patients with RA in the present report. In patients with malignant mesothelioma, HYA has been supposed to originate from the tumour tissue [29], but according to cell culture studies a mesothelioma-induced production of HYA by surrounding normal mesothelial cells and fibroblasts may occur [30].

Despite the abundance of HYA in rheumatoid effusions, the fluid is not viscous, a feature sometimes seen in malignant mesothelioma. The low viscosity of rheumatoid synovial fluid has been explained by an increased production of incompletely polymerized HYA and dilution of high molecular weight HYA [2], and by degradation of high molecular weight HYA [31].

Depolymerization of HYA could be caused by free oxygen-derived radicals, mainly hydroxyl radicals, produced by macrophages and polymorphonuclear leukocytes in the rheumatoid synovium $[20,31,32]$. The molecular weight of Pf-HYA was not analysed in the present study, but there may be common mechanisms behind the low viscosity of Pf-HYA in rheumatoid pleural and synovial fluids.

Elevated S-HYA may be due to increased biosynthesis or increased release, or to a diminished clearance caused by hepatic dysfunction. In concordance with previous reports, a median S-HYA exceeding the upper normal range was seen in RA. Elevation of S-HYA in RA may depend on increased synovial production and outflow of HYA from the joints to the circulation [33]. It was not possible to confirm previous reports of elevated S-HYA in patients with mesothelioma $[10,34]$, perhaps because serum samples were taken when the disease was still confined to one side of the thoracic cavity. Elevated S-HYA in some individuals with $\mathrm{CHF}$ was probably caused by a reduced clearance of HYA due to diminished hepatic blood flow [35].

In conclusion, high pleural fluid hyaluronan is not exclusively observed in malignant mesothelioma but also in inflammatory diseases, such as rheumatoid arthritis. In inflammatory pleural diseases, local production of proinflammatory cytokines may account for the increase in pleural fluid hyaluronan. 


\section{References}

1. Dahl IMS, Husby G. Hyaluronic acid production in vitro by synovial lining cells from normal and rheumatoid joints. Ann Rheum Dis 1985; 44: 647-657.

2. Dahl LB, Dahl IMS, Engström-Laurent A, Granath K. Concentration and molecular weight of sodium hyaluronate in synovial fluid from patients with rheumatoid arthritis and other arthropathies. Ann Rheum Dis 1985; 44: 817-822.

3. Butler DM, Vitti GF, Leizer T, Hamilton JA. Stimulation of the hyaluronic acid levels of human synovial fibroblasts by recombinant human tumor necrosis factor $\alpha$, tumor necrosis factor $\beta$ (lymphotoxin), interleukin- $1 \alpha$, and interleukin-1ß. Arthritis Rheum 1988; 31: 1281-1289.

4. Engström-Laurent A, Lööf L, Nyberg A, Schröder T. Increased serum levels of hyaluronate in liver disease. Hepatology 1985; 8: 638-642.

5. Engström-Laurent A, Hällgren R. Circulating hyaluronate in rheumatoid arthritis: relationship to inflammatory activity and the effect of corticosteroid therapy. Ann Rheum Dis 1985; 44: 83-88.

6. Lundin A, Engström-Laurent A, Hällgren R, Michelsson G. Circulating hyaluronate in psoriasis. $\mathrm{Br} J$ Dermatol 1985; 112: 663-671.

7. Engström-Laurent A, Feltelius N, Hällgren R, Wasteson A. Raised serum hyaluronate levels in seleroderma: an effect on growth factor-induced activation of connective tissue cells? Ann Rheum Dis 1985; 44: 614-622.

8. Berg S, Brodin B, Hesselvik F, Laurent TC, Maller R. Elevated levels of plasma hyaluronan in septicaemia. Scand J Clin Lab Invest 1988; 48: 727-732.

9. Hällgren R, Samuelsson T, Laurent TC, Modig J. Accumulation of hyaluronan (hyaluronic acid) in the lung in adult respiratory distress syndrome. Am Rev Respir Dis 1989; 139: 682-687.

10. Frebourg T, Lerebours G, Delpech B, et al. Serum hyaluronate in malignant pleural mesothelioma. Cancer 1987; 59: 2104-2107.

11. Roboz J, Greaves J, Silides D, Chahinian AP, Holland JF. Hyaluronic acid content of effusions as a diagnostic aid for malignant mesothelioma. Cancer Res 1985; 45: 1850 1854.

12. Mårtensson G, Thylén A, Lindqvist U, Hjerpe A. The sensitivity of hyaluronan analysis of pleural fluid from patients with malignant mesothelioma and a comparison of different methods. Cancer 1994; 73: 1406-1410.

13. Pettersson T, Fröseth B, Riska H, Klockars M. Concentration of hyaluronic acid in pleural fluid as a diagnostic aid for malignant mesothelioma. Chest 1988; 94: 10371039.

14. Arnett FC, Edworthy SM, Bloch DA, et al. The American Rheumatism Association 1987 revised criteria for the classification of rheumatoid arthritis. Arthritis Rheum 1988; 31: $315-324$.

15. Teppo AM, Maury CPJ. Radioimmunoassay of tumor necrosis factor in serum. Clin Chem 1987; 33: 2024-2027.

16. Cannon JG, van der Meer JWM, Kwiatkowski D, et al. Interleukin-1 $\beta$ in human plasma: optimization of blood collection, plasma extraction, and radioimmunoassay methods. Lymphokine Res 1988; 7: 457-467.

17. Thylén A, Levin-Jacobsen A-M, Hjerpe A, Mårtensson G. Immunohistochemical differences between hyaluronan- and non-hyaluronan-producing malignant mesothelioma. Eur Respir J 1997; 10: 404-408.

18. Laurent TC, Fraser JRE. The properties and turnover of hyaluronan. In: Evered D, Whelan J, eds. Function of the proteoglycans. Ciba Foundation Symposium 124. Chichester, John Wiley 1986; pp. 9-29.

19. Yaron I, Meyer FA, Dayer J-M, Yaron M. Human recombinant interleukin-1 $\beta$ stimulates glycosaminoglycan production in human synovial fibroblast cultures. Arthritis Rheum 1987; 30: 424-430.

20. Haubeck H-D, Kock R, Fischer D-G, Van de Leur E, Hoffmeister K, Greiling H. Transforming growth factor $\beta 1$, a major stimulator of hyaluronan synthesis in human synovial lining cells. Arthritis Rheum 1995; 38: 669-677.

21. Hiro D, Ito A, Matsuta K, Mori Y. Hyaluronic acid is an endogenous inducer of interleukin-1 production by human monocytes and rabbit macrophages. Biochem Biophys Res Commun 1986; 140: 715-722.

22. Goa KL, Benfield P. Hyaluronic acid. A review of its pharmacology and use as a surgical aid in ophthalmology, and its therapeutic potential in joint disease and wound healing. Drugs 1994; 47: 536-566.

23. West DC, Kumar S. Hyaluronan and angiogenesis. In: Evered D, Whelan J, eds. The Biology of Hyaluronan. Ciba Foundation Symposium 143. Chichester, John Wiley, 1989; pp. 187-201.

24. Bjermer L, Engström-Laurent A, Lundgren R, Rosenhall L, Hällgren R. Hyaluronate and type III procollagen peptide concentrations in bronchoalveolar lavage fluid as markers of disease activity in farmer's lung. $\mathrm{Br}$ Med $J$ 1987; 295: 803-806.

25. Milman N, Kristensen MS, Bentsen K, Grode G, Frederiksen J. Hyaluronan and procollagen type III aminoterminal peptide in serum and bronchoalveolar lavage fluid in patients with pulmonary sarcoldosis. Sarcoidosis 1995; 12: $38-41$.

26. Lavö B, Knutson L, Lööf L, Odlind B, Hällgren R. Signs of increased leakage over the jejunal mucosa during gliadin challenge of patients with coeliac disease. Gut 1990; 31: $153-157$.

27. Edelstam GAB, Lundkvist Ö, Venge P, Laurent TC. Hyaluronan and myeloperoxidase in human peritoneal fluid during genital inflammation. Inflammation 1994; 18: 1321.

28. Hillerdal G, Lindqvist U, Engström-Laurent A. Hyaluronan in pleural effusions and in serum. Cancer 1991; 67: 2410-2414.

29. Nakano T, Fujii J, Tamura S, et al. Glycosaminoglycan in malignant pleural mesothelioma. Cancer 1986; 57: 106110.

30. Asplund T, Versnel MA, Laurent TC, Heldin P. Human mesothelioma cells produce factors that stimulate the production of hyaluronan by mesothelial cells and fibroblasts. Cancer Res 1993; 53: 388-392.

31. Schenck P, Schneider S, Miehlke R, Prehm P. Synthesis and degradation of hyaluronate by synovia from patients with rheumatoid arthritis. J Rheumatol 1995; 22: 400405.

32. Saari H. Oxygen derived free radicals and synovial fluid hyaluronate. Ann Rheum Dis 1991; 50: 389-392.

33. Engström-Laurent A, Hällgren R. Circulating hyaluronic acid levels vary with physical activity in healthy subjects and in rheumatoid arthritis patients: relationship to synovitis mass and morning stiffness. Arthritis Rheum 1987; 30: 1333-1338.

34. Dahl IMS, Laurent TC. Concentration of hyaluronan in the serum of untreated cancer patients with special reference to patients with mesothelioma. Cancer 1988; 62: 326-330.

35. Laurent TC, Laurent UBG, Fraser JRE. Serum hyaluronan as a disease marker. Ann Med 1996; 28: 241-253. 